Cataract

\title{
Self assessed benefit of cataract extraction
}

\section{N Congdon}

\section{Renewed vision for years to come}

C ataract is the leading cause of blindness in the world, ${ }^{1}$ and the leading cause of low vision in European derived populations. ${ }^{2}$ The burden of cataract is likely to increase as the world's population ages. ${ }^{2}$ At present, no effective means of preventing cataract exists, with the possible exception of smoking cessation. ${ }^{3}$ For the foreseeable future, the sole method of preventing cataract blindness will remain the surgical removal of the opacified lens. Fortunately, successful results are the rule rather than the exception with cataract surgery in the developed world ${ }^{4-6}$ and many parts of the developing world. ${ }^{78}$ Fully $90 \%$ of people undergoing cataract surgery can expect to attain vision of $6 / 12$ or better postoperatively, ${ }^{45}$ and a similar proportion report being satisfied with their surgery. ${ }^{6}$

The fact that cataract remains an important cause of blindness in the developing world, and even in parts of the developed world, ${ }^{9}$ suggests that a commitment to improved access to cataract surgical services is required. However, the widespread provision of such services can be expensive: the annual cost of cataract surgery in the United States, for example, exceeds \$US3 billion, ${ }^{10}$ and some two thirds of the US Medicare budget is expended on the examination and treatment of cataract. $^{11}$ The strongest argument in favour of increasing expenditures to combat cataract blindness has been the contention that cataract extraction is a highly cost effective surgery. ${ }^{12}{ }^{13}$ However, as the authors of the paper in this issue of the BJO (p 1017), note, "three variables must be known in order to support (the) statement (that cataract surgery is cost effective)." While data on the cost of cataract surgery and its impact on vision have generally been widely available, the paper by Lundstrom and Wendel is one of the first to provide evidence on the duration of improved visual function after surgery.

While Lundstrom and Wendel indicate that the proportion of subjects reporting improved vision after surgery declines, not surprisingly, with longer follow up, their conclusion that $80 \%$ still have improved function 7 years after surgery is, none the less, extremely encouraging. Healthcare policy makers and governmental and non-governmental organisations engaged in the provision of eye care should be motivated by the fact that currently available surgical treatment for the world's leading cause of blindness is capable not only of bringing renewed sight now, but for many years to come.

Br J Ophthalmol 2005;89:931.

doi: 10.1136/bjo.2005.068114

Correspondence to: $\mathrm{N}$ Congdon, Wilmer Eye Institute John Hopkins Hospital $600 \mathrm{~N}$ Wolfe Street Baltimore, MD 21287, USA; ncongdon@ jhmi.edu

\section{REFERENCES}

1 Thylefors B, Negrel AD, Pararajasegaram R, et al. Global data on blindness. Bull World Health Organization 1995;73:115-21.

2 Congdon N, O'Colmain B, Klaver CC, et al. Causes and prevalence of visual impairment among adults in the United States. Arch Ophthalmol 2004:122:477-85.

3 McCarty CA, Nanjan MB, Taylor HR. Attributable risk estimates for cataract to prioritize medical and public health action. Invest Ophthalmol Vis Sci 2000:41:3720-5.

4 Desai P, Minassian DC, Reidy A. National cataract surgery survey 1997-98: a report of the results of clinical outcomes. Br J Ophthalmol 1999;83:1336-40.

5 Stenevi U, Lundstrom M, Thorburn W. An outcome study of cataract surgery based on a national register. Acta Ophthalmol Scand 1997;75:688-91.

6 Lundstrom M, Stenevi U, Thorburn W, et al Catquest questionnaire for use in cataract surgery care: assessment of surgical outcomes. J Cataract Refract Surg 1998;24:968-74

7 Prajna NV, Chandrakanth KS, Kim R, et al. The Madurai Intra-Ocular Lens Study. II: Clinical outcomes, Am J Ophthalmol 1998;125:14-25.

8 Yorston D, Foster A. Audit of extra-capsular cataract extraction and posterior chamber lens implantation as a routine treatment for agerelated cataract in East Africa. $\mathrm{Br} J$ Ophthalmol 1999:83:897-901.

9 Sommer A, Tielsch JM, Katz J, et al. Racial differences in the cause-specific prevalence of blindness in east Baltimore. N Engl J Med 1991:325:1412-17.

10 Javitt JC. Who does cataract surgery in the United States? Arch Ophthalmol 1993;111:1329.

11 Ellwein LB, Urato CJ. Use of eye care and associated charges among the Medicare population: 1991-98. Arch Ophthalmol 2002;120:804-11.

12 Kobelt G, Lundstrom M, Stenevi U. Measuring utility and outcome in cataract surgery. J Cataract Refract Surg 2002;28:1742-9.

13 Busbee BG, Brown MM, Brown GC, et al. Incremental cost-effectiveness of initial cataract surgery. Ophthalmology 2002; 109:606-13.

\section{Intravitreal triamcinolone therapy for diabetic macular oedema}

\section{S A Vernon}

\section{Which dosage should we use?}

$\mathrm{t}$ is less than 4 years ago since publication of the first report on the use of crystalline cortisone in the form of triamcinolone acetonide to treat recalcitrant macular oedema in patients with diabetes. ${ }^{1}$ This report of a single eye was rapidly followed by a case series from the same author (Jonas), ${ }^{2}$ who has remained faithful to a dosage regimen of $20 \mathrm{mg}$ in a number of publications documenting the efficacy and side effects of this novel form of therapy. ${ }^{3-8}$ In parallel with Jonas, Martidis and co-workers in the United States ${ }^{9}$ reported on the use of a $4 \mathrm{mg}$ dosage in a similar clinical scenario. Since then there have been many reports, including early results from a randomised controlled trial (RCT), utilising this somewhat lower dosage. ${ }^{10-15}$ All studies have thus far indicated a significant improvement in macular function and/or structure following injection, at least in the short term. 
Why have different dosage regimens been employed? Triamcinolone acetonide is conveniently and affordably available in concentrations of $40 \mathrm{mg} / \mathrm{ml}$ in a sterile preparation (Kenolog, or Volon A or Kenacort depending on country, Bristol-Myers-Squibb) used commonly in other specialties such as orthopaedics. As $0.1 \mathrm{ml}$ is the maximum volume most eyes can tolerate when injected into the vitreous cavity without causing inevitable central retinal artery occlusion, the maximum dosage of unadulterated triamcinolone one can give at any one time without resorting to paracentesis is clearly $4 \mathrm{mg}$. Jonas concentrates the triamcinolone crystals using a filter and then injects (after a routine paracentesis) $0.2 \mathrm{ml}$ of a suspension of triamcinolone and Ringer's solution $(0.4 \mathrm{ml}$ in the comparative dosage study in this issue of the BJO (p 999)).

In the aforementioned study, a small RCT comparing the efficacy of three dosages of triamcinolone (assayed to be $2 \mathrm{mg}, 5 \mathrm{mg}$, and $13 \mathrm{mg}$ of injected triamcinolone), Spandau and colleagues from Jonas's team make a case for the use of the higher dosage in diabetic macular oedema (13 mg was found to be the equivalent of a $20 \mathrm{mg}$ stated dose in Jonas's previous studies). This was based upon a significantly improved outcome in terms of maximum distance visual acuity in the $13 \mathrm{mg}$ group compared with the $2 \mathrm{mg}$ group (but notably not the $5 \mathrm{mg}$ group-a dosage closest to that probably injected in all other series), and a finding of a significant dose/duration effect correlation when all three doses were considered. There are a number of unanswered questions posed by the study such as the duration of oedema before treatment and the numbers in each group who had received laser treatment. It would also be tempting to discount this small study after viewing the data points on the figures where it can be seen that one or two eyes in the $13 \mathrm{mg}$ group appear to be having a disproportionate influence on the results. The results, however, appeal somewhat intuitively, and merit further consideration.

\section{Whether vitrectomy or intravitreal triamcinolone, perhaps combined with cataract surgery, proves to be optimal for an individual patient/ eye will require much more research}

Examination of the literature, comparing Jonas's results with those of others, fails to create a clearcut difference in outcome between dosage regimens for many reasons. These include differing entry criteria (with or without previous macular laser, duration of oedema, levels of acuity at baseline), methods of acuity measurement (EDTRS chart versus Snellen chart), the presence or lack of supporting evidence of efficacy such as optical coherence tomography (OCT), and methods of comparison (randomised trial versus non-randomised case or case-control series). However, a common feature of all series extending to 6 months or longer is a rapid improvement phase, followed by a plateau phase and then regression, at least in some eyes.

Martidis et al, ${ }^{9}$ using $4 \mathrm{mg}$, reported that three of the eight eyes at 6 months required re-injection for recurrence of oedema with loss of vision. In the study by Massin et al ${ }^{11}(4 \mathrm{mg}$ ), the difference in macular thickness (which correlates well with visual improvement) measured by OCT at 6 months compared with baseline had become non-significant owing to recurrence of oedema in five of the 12 injected eyes. In addition, at no stage was there a significant difference between the acuity in treated and the control (untreated) eyes. However, Sutter et al (RCT with $4 \mathrm{mg}$ versus subconjuctival placebo), ${ }^{10}$ at 3 months, showed a significant visual improvement in treated eyes with $24 \%$ improving by 10 or more EDTRS letters. In the study by Ciardella et al, ${ }^{12} 8 / 30$ $(27 \%)$ of eyes had received at least one re-injection (again $4 \mathrm{mg}$ ) because of recurrence of oedema at a median time of 6 months between the first and second injection. Audren et al, ${ }^{16}$ used pharmacokinetic-pharmacodynamic modelling of OCT readings, estimated the mean maximum duration of effect of a $4 \mathrm{mg}$ injection to be 140 days. In Jonas's largest series to date, in which triamcinolone was the only treatment for diabetic macular oedema, a dosage of $20 \mathrm{mg}$ (probably $13 \mathrm{mg}$ active triamcinlone) resulted in an improvement of at least two Snellen lines in $68 \%$ of the 97 treated eyes with a mean increase of 2.6 lines at best. ${ }^{4}$ There was no tendency to regress over the first 4 months following injection but by 6 months the effect of injection on acuity had become insignificant in a group analysis, a finding similar to our own series ${ }^{13}$ utilising a $4 \mathrm{mg}$ injection.

The lack of any comparative data on lens morphology and density and macular thickness in Spandau's study is unfortunate as acuity some months after injection may be compromised by cataract formation. ${ }^{17}$ Comparative data on all aspects of visual function, including the much neglected reading ability $^{13} 18$ and complication rates, in particular cataract and glaucoma, will only be answered by further prospective RCTs, which should begin to utilise subjective patient generated outcome measures relating visual improvement to time of perceived benefit.

The use of intravitreal triamcinolone has given new hope to many patients with chronic diabetic macular oedema often permitting them to read again, even if only for a few months. ${ }^{13} 18$ Whether vitrectomy ${ }^{19}$ or intravitreal triamcinolone, perhaps combined with cataract surgery, ${ }^{20}$ proves to be optimal for an individual patient/eye will require much more research. The National Eye Institute in the United States has funded studies examining the efficacy of intraocular steroids in diabetic retinopathy and retinal vein occlusion. ${ }^{21}$ Those practising elsewhere should take into account the results from Professor Jonas's team when formulating their protocols for similar research.

Br J Ophthalmol 2005;89:931-933. doi: $10.1136 /$ bjo.2005.065805

Correspondence to: S A Vernon, Department of Ophthalmology, Queens Medical Centre, University Hospital, Nottingham NG7 2UH, UK; stephen.vernon@qmc.nhs.uk

Competing interests: none declared

\section{REFERENCES}

1 Jonas JB, Sofker A. Intraocular injection of crystalline cortisone as adjunctive treatment of diabetic macular edema. Am J Ophthalmol 2001; 132:425-7.

2 Jonas JB, Kreissig I, Sofker A, et al. Intravitreal injection of triamcinolone for diffuse diabetic macular edema. Arch Ophthalmol 2003;121:57-61.

3 Jonas JB, Harder B, Kamppeter BA. Inter-eye difference in diabetic macular edema after unilateral intravitreal injection of triamcinolone acetonide. Am J Ophthalmol 2004;138:970-7.

4 Jonas JB, Akkoyun I, Kreissig I, et al. Diffuse diabetic macular oedema treated by intravitreal triamcinolone acetonide: a comparative, nonrandomised study. $\mathrm{Br} J$ Ophthalmol 2005;89:321-6.

5 Jonas JB, Kreissig I, Degenring RF, et al. Repeated intravitreal injection of triamcinolone acetonide for diffuse diabetic macular oedema. Br J Ophthalmol 2005;89:122.

6 Jonas JB, Degenring R, Kreissig I, et al. Safety of intravitreal high-dose reinjections of triamcinolone acetonide. Am J Ophthalmol 2004; 138: 1054-5

7 Jonas JB, Degenring RF, Kamppeter BA, et al. Duration of the effect of intraviteal triamcinolone acetonide as treatment for diffuse diabetic macular edema. Am J Ophthalmol 2004; 138: 158-60

8 Jonas JB, Kreissig I, Degenring R. Intraocular pressure after intravitreal injection of triamcinolone acetonide. $\mathrm{Br} J$ Ophthalmo 2003;87:24-7

9 Martidis A, Duker JS, Greenberg PB, et al. Intravitreal triamcinolone for refractory diabetic macular edema. Ophthalmology 2002; 109:920-7.

10 Sutter FKP, Simpson JM, Gillies MC. Intravitreal traimcinolone for diabetic macular edema that persists after laser treatment. Ophthalmology 2004; 111:2044-9.

11 Massin P, Audren F, Haouchine B, et al. Intravitreal triamcinolone acetonide for diffuse diabetic macular edema-preliminary results of a prospective controlled trial. Ophthalmology 2004; 111:218-25.

12 Ciardella AP, Klancnik J, Schiff W, et al. Intravitreal triamcinolone for the treatment of refractory diabetic macular oedema 
with hard exudates: an optical coherence tomography study. $\mathrm{Br} J$ Ophthalmol 2004;88:1131-6.

13 Negi AK, Vernon SA, Lim CS, et al. Intravitreal triamcinolone improves vision in eyes with chronic diabetic macular oedema refractory to laser photocoagulation. Eye 2004 [Epub ahead of print].

14 Lam DSC, Chan CKM, Tang EWH, et al. Intravitreal triamcinolone for diabetic macular oedema in Chinese patients: six-month prospective longitudinal pilot study. Clin Exp Ophthalmol 2004:32:569-72.

15 Karacorlu M, Ozdemir H, Karacorlu S, et al. Intravitreal triamcinolone as a primary therapy in diabetic macular oedema. Eye 2004 [Epub ahead of print].

16 Audren F, Tod M, Massin P, et al. Pharmacokinetic-Pharmacodynamic modelling of the effect of triamcinolone acetonide on central macular thickness in patients with diabetic macular edema. Invest Ophthalmol Vis Sci 2004:45:3435-41.

17 Gillies MC, Simpson JM, Billson FA, et al. Saftey of an intravitreal injection of triamcinoloneresults from a randomised clinical trial. Arch Ophthalmol 2004; 122:336-40.

18 Islam MS, Negi A, Vernon SA. Improved visual acuity and macular thickness 1 week after intravitreal triamcinolone for diabetic

\section{A revolution in Welsh low vision service provision}

\section{T H Margrain, B Ryan, J M Wild}

Failure of the service in Wales was perhaps best reflected in the inadequate number of low vision assessments

P

eople in Wales with impaired vision have recently benefited from the arrival of a new nationwide community based low vision service. Undoubtedly, this is a dramatic and welcome development for all those with untreatable sight loss, not just those registered blind or partially sighted. But what has motivated the Welsh Assembly to take this radical step?

One reason is that visual impairment in Wales, like the rest of the United Kingdom, is reaching epidemic proportions. Since 1982, the number of people in the United Kingdom registered blind and partially sighted $^{1}$ has almost doubled and now stands at $359000 .^{2-4}$ However, the registers are known to underestimate the number with untreatable sight loss by a factor of twofold to threefold and so there may be more than 1000000 people in the United Kingdom with untreatable low vision. ${ }^{5} 6$ This estimate is supported by a recent Medical Research Council trial that has established that one in five people over the age of 75 have a binocular visual acuity below 6/12. ${ }^{7}$ In many parts of Wales, the combined prevalence of registerable visual impairment (that is, both blind and partial sight registrations) now exceeds $2 \% .^{8}$ The magnitude of the problem will undoubtedly increase because most sight threatening eye disease is age related and the number of people aged 60 and over is projected to increase by $57 \%$ over the next 30 years.'
Another reason for the Welsh Assembly's decision is that the cost of failure to provide an effective low vision service is high. Without appropriate rehabilitation, visual loss can have a devastating impact on the individual and is associated with depression, falls, and loss of independence. ${ }^{10}$ The cost to society is no less significant. A recent review of the costs associated with blindness has highlighted the scale of the economic impact of visual impairment and suggests that the annual UK bill for residential care, just for those on the blind register, is approximately $£ 715$ million. ${ }^{10}$

Thankfully, the impact of visual impairment can be reduced by an effective low vision service. Low vision services have traditionally operated at the interface between healthcare and social care involving ophthalmologists, optometrists, social workers, and rehabilitation workers. The service helps people with visual impairment to remain independent by providing low vision aids such as magnifiers, which optimise residual vision, and by appropriate rehabilitation training. ${ }^{11}$ Although many studies have shown low vision service provision to be beneficial in terms of functional ability and patient satisfaction $^{12-17}$ the effect on quality of life is less clear-that is, while low vision service provision appears to improve some aspects of vision related quality of life (in particular, those that relate to near vision and reading) it macular oedema. Eye 2004 [Epub ahead of print].

19 Yamamoto T, Akabane N, Takeuchi S. Vitrectomy for diabetic macular edema: the role of posterior vitreous detachment and epimacular membrane. Am J Ophthalmol 2001;132:369-77.

20 Lam DSC, Chan CKM, Mohamed S, et al. Phacoemulsification with intravitreal triamcinolone in patients with cataract and coexisting diabetic macular oedema: a six-month prospective pilot study. Eye, 2004 [Epub ahead of print]

21 Flynn HW Scott IU Intravitreal triamcinolone acetonide for macular edema associated with diabetic retinopathy and venous occlusive disease. Arch Ophthalmol 2005;123:258-9. does not improve all aspects. ${ }^{15} 17$ Furthermore, it appears that more complex services, involving supplementary home based low vision rehabilitation, are no better at improving vision related quality of life than conventional (hospital based) low vision rehabilitation. ${ }^{18}$

Access to the new service has been optimised by ensuring that services are geographically spread throughout Wales

In reality, however, there has never been a "low vision service." Instead, there is a patchwork of services, excellent in some areas and woefully inadequate in others-that is, a true postcode lottery. A survey of low vision service provision in the United Kingdom in 1998 highlighted the fragmented nature of the service with differences in availability and accessibility and a lack of communication between healthcare and social care professionals. ${ }^{8}$ A review of services in 2001 showed that one of the main problems in Wales was service access. ${ }^{19}$ Like many other parts of the United Kingdom, access to low vision services in Wales was restricted by a convoluted referral route typically involving referral from an optometrist to a general practitioner to an ophthalmologist and, eventually, on to a low vision service provider, and then to social services. A survey of waiting times showed that in some parts of Wales people with low vision had to wait up to 18 months to access a low vision service. ${ }^{19}$ Access in Wales has also been restricted by the poor geographical distribution of services. People with a visual impairment, many of whom are elderly and with multiple disabilities, were frequently required to make a round trip of 100 miles or more, often on routes not served by public transport, to reach the nearest service provider. Failure of the service in Wales was perhaps best reflected in the inadequate number of low vision assessments. In 2000, there were only 4500 low vision assessments serving a visually impaired 
population of at least 55000 - that is, a single assessment for every 12 people who might benefit. ${ }^{19}$

In recognition of these factors, the National Assembly in Wales has taken the radical step of introducing a nationwide low vision service. The new service, which opened its doors in the summer of 2004, is based on the conventional hospital eye service model but is located in community based optometric practices and exists alongside established services in secondary care. It is staffed by accredited optometrists and a limited number of dispensing opticians, who have successfully passed a theoretical and practical course in low vision administered by Cardiff University, working in close association with ophthalmologists, social services, education, and the voluntary sector. Waiting times are expected to be less than 2 weeks. Low vision aids are provided on a loan basis and home visits are made where necessary. A "vision passport" has been introduced which, like the "personal child health record," promotes individual empowerment, provides information, and facilitates inter-agency communication. Access to the new service has been optimised by ensuring that services are geographically spread throughout Wales. Currently, 95 optometrists, nine dispensing opticians, and one ophthalmic medical practitioner have been accredited (about one quarter of the optometrists in Wales) and a further 120 are undergoing training or have shown an interest (contact details can be obtained from the corresponding author). It is estimated that low vision services are provided at 121 sites across Wales. Referrals into the service are accepted from general practitioners, ophthalmologists, optometrists, social services, and from individual patients themselves. Indeed, anyone whose visual acuity is 6/12 or less, N6 or less, or whose field is significantly restricted, may access the service.

The arrival of the first national low vision service in Wales is a welcome and, some would say, long overdue development. In all, 1166 people were seen by Christmas 2004; $87 \%$ were seen within 2 weeks and 95\% within a month. With improved access and universal coverage, the service should enable everyone living in the Principality with impaired sight to continue to make best use of their sight. Of course, the service is being audited and the impact on those that use it will be evaluated. Evaluation of the effectiveness of visual rehabilitation is essential and funding for this evaluation has been built into the service. Even if the service is found to be effective in Wales it may not be the most appropriate model for all parts of the United Kingdom. Indeed, in Northern Ireland, 10 new outreach clinics have been established in secondary care, ${ }^{20}$ and in England four pilot services have been funded under the new Eye Care Pathways project, ${ }^{21}$ and 66 local low vision service committees have been set up. However, half a decade on from the publication of recommendations for future low vision service delivery, ${ }^{22}$ endorsed by the then secretary of state for health, many people with low vision in the United Kingdom are still not receiving low vision care. We hope that it is not too long before everyone with low vision in the United Kingdom can benefit from assured investment in these important services.

Br J Ophthalmol 2005;89:933-934. doi: $10.1136 /$ bjo.2005.066142

\section{Authors' affiliations}

T H Margrain, B Ryan, J M Wild, School of Optometry and Vision Sciences, Cardiff University, Cardiff CF10 3NB, UK

Correspondence to: Tom H Margrain, School of Optometry and Vision Sciences, Cardiff University, Cardiff CF10 3NB, UK; margrainth@cardiff.ac.uk

\section{REFERENCES}

1 Evans J. Causes of blindness and partial sight in England and Wales 1990-1991. Studies on medical and population subjects, no 57. London: HMSO, 1995.

2 Local Government Data Unit Wales. Register of physical and sensory disabled people, 31 March 2003. Cardiff: National Assembly for Wales, 2004.

3 Scottish Executive. Registered blind and partially sighted persons, Scotland 2003. Edinburgh: Scottish Executive National Statistics Publication, 2003.
4 Department of Health. Registered blind and partially sighted people year ending 31 March 2003 England. London: National Statistics, 2003

5 Reidy A, Minassian DC, Vafidis G, et al. Prevalence of serious eye disease and visual impairment in a north London population: population based, cross sectional study. BMJ 1998;316:1643-6.

6 Bruce I, McKennell A, Walker E. Blind and partially sighted adults in Britain: the RNIB survey. London: HMSO, 1991

7 Evans JR, Fletcher AE, Wormald RPL, et al. Prevalence of visual impairment in people aged 75 years and older in Britain: results from the 75 years and older in Britain: results from the
MRC trial of assessment and management of older people in the community. Br J Ophthalmol 2002:86:795-800

8 Ryan B, Culham L. Fragmented vision; survey of low vision services in the UK. London: Royal National Institute for the Blind, 1999

9 Shaw C. 2002-Based national population projections for the United Kingdom and constituent countries. Population Trends No 115 London: HMSO, 2004.

10 Meads C, Hyde C. What is the cost of blindness? Br J Ophthalmol 2003;87:1201-4.

11 Margrain TH. Minimising the impact of visual impairment: low vision aids are a simple way of alleviating impairment. BMJ 1999;318:1504

12 Leat SJ, Fryer A, Rumney NJ. Outcome of low vision aid provision: the effectiveness of a low vision clinic. Optom Vis Sci 1994;71:199-206.

13 Shuttleworth GN, Dunlop A, Collins JK, et al. How effective is an integrated approach to low vision rehabilitation? Two year follow up results from south Devon. Br J Ophthalmol 1995;79:719-23.

14 Margrain TH. Helping blind and partially sighted people to read: the effectiveness of low vision aids. Br J Ophthalmol 2000;84:919-21.

15 Wolffsohn JS, Cochrane AL. Design of the low vision quality-of-life questionnaire (LVQOL) and measuring the outcome of low-vision rehabilitation. Am J Ophthalmo 2000;130:793-802.

16 Stelmack JA, Stelmack TR, Massof RW Measuring low-vision rehabilitation outcomes with the NEI VFQ-25. Invest Ophthalmol Vis Sci 2002;43:2859-68.

17 Hinds A, Sinclair A, Park J, et al. Impact of an interdisciplinary low vision service on the quality of life of low vision patients. Br J Ophthalmol 2003;87:1391-6.

18 Reeves BC, Harper RA, Russell WB. Enhanced low vision rehabilitation for people with age related macular degeneration: a randomised controlled trial. $\mathrm{Br} J$ Ophthalmol 2004:88:1443-9.

19 Furze H, Margrain TH, Wigham C. Provision of low vision care in Wales. Cardiff: National Assembly for Wales, 2001.

20 Lindsay J, Bickerstaff D, McGlade A, et al. Low vision service delivery: an audit of newly developed outreach clinics in Northern Ireland. Ophthal Physiol Opt 2004;24:360-86.

21 National Eye Care Services Steering Group. First report of the National Eye Care Services Steering Group. London: Department of Health, 2004.

22 Royal National Institute for the Blind. Low Vision Services Consensus Group. Low vision services: recommendations for future service delivery in the UK. London: RNIB, 1999 